\title{
Serviços Bancários pela Internet: um Estudo de Caso Integrando a Visão de Competidores e Clientes
}

\author{
Anatália Saraiva Martins Ramos \\ Fabrício de São Paulo H. A. Rubim Costa
}

\section{RESUMO}

O comércio eletrônico pela Internet ou Internet commerce, restrito no presente estudo ao segmento das instituições financeiras, será focado a partir da análise do uso de serviços bancários pela Internet, particularmente o serviço de personal banking do Banco do Brasil, em que serão abordados aspectos comparativos com seus principais competidores e a visão de seus usuários. O estudo se baseia em investigação de seis grandes sites de bancos e também se utiliza de uma pesquisa de campo, que envolve amostra de clientes de uma agência do Banco do Brasil para complementar o estudo a partir da visão do usuário. Por meio dos resultados da pesquisa, numa abordagem situacional de identificação das barreiras a superar e sugestões de melhorias, as áreas de tecnologia de informação e marketing de bancos poderão montar uma estratégia em face da concorrência, no sentido de melhorar a posição competitiva no mercado.

Palavras-chaves: comércio eletrônico; Internet; serviços bancários; competitividade.

\begin{abstract}
The present paper aims to show the e-commerce in the segment of financial institution, in which will be analyzed the use of banking services on the Web, particularly the service of the personal banking of the Banco do Brasil, where will be studied comparatives aspects with its main competitors and customers perceptions. This work is substantiated not only in investigation of websites but also in exploratory research involving customers of a agency of the Banco do Brasil. Utilizing the findings of the research, the Banco do Brasil could be able to build a strategy toward the competitive advantage in order to improve its position because of both the identification of barriers that it has to overcome and suggestions of benefits.
\end{abstract}

Key words: electronic commerce; Internet; banking services; competitiveness. 


\section{INTRODUÇÃO}

O fenômeno da Internet em nível comercial desencadeou uma abrupta expansão tecnológica e o aperfeiçoamento das transmissões de dados e do compartilhamento de informações via computadores, o aparecimento de novas formas de comercialização de produtos e serviços, dando início ao que se denominou de Internet commerce, comércio pela Internet, além de outras denominações (ecommerce, e-business, digital markets etc). Observa-se que este tema vem sendo cada vez mais enfocado, tanto na literatura de negócios quanto no âmbito acadêmico, dada a sua importância no contexto atual de um mercado cada vez mais exigente e competitivo (Schwartz, 1997; Albertin, 1998; Mougayar, 1998; Downes e Mui, 1998; Seybold, 1998).

Torna-se relevante, portanto, pesquisar temas que enfoquem a estratégia de uso da Internet nos setores produtivos, em particular as instituições bancárias, a fim de poder contribuir com o conhecimento da realidade destas empresas, para de alguma forma auxiliar na obtenção de vantagem em termos de competitividade.

\section{A Internet como Propiciadora da Integraçāo Digital}

O fenômeno da Internet já se configura como uma das grandes inovações tecnológicas e organizacionais no mundo empresarial deste século. Projeções da NUA Internet Surveys, renomada empresa de consultoria de tendências para a Internet, indicam que existem aproximadamente 200 milhões de pessoas em todo o mundo que estão usando alguns dos serviços da Internet ${ }^{(1)}$. No caso do Brasil, diversas empresas de pesquisas, tais como Computer Industry Almanac, Brazilian ISC, IDC e IBOPE, estimam que há mais de 3 milhões de brasileiros conectados à Internet ${ }^{(2)}$. Para o IBOPE, 7\% da população brasileira usa o computador para acessar a Internet, com perspectiva de aumentar esta participação relativa. Para seus analistas, isto se deve à tendência natural do mercado e à popularização da Internet ${ }^{(3)}$.

Milhares de usuários podem acessá-la na comodidade das suas casas, via computador. Devido aos grandes investimentos alocados na área de informática, tornando essa tecnologia mais acessível, era de se esperar tal incremento. É a mídia que mais rapidamente abocanhou um público alvo de 40 milhões de pessoas, 
isso em apenas 5 anos. O rádio levou 40 anos, a televisão 20 anos e a TV a cabo, 10 anos (TV Senac, 1998).

Essas inovações no campo da tecnologia da informação têm causado uma reviravolta na forma de atuar das organizações, que devem preparar-se para se ajustar à realidade emergente e reinventar seus negócios com base na world wide web (Donovan, 1997). A multimídia interativa e a Internet estão possibilitando uma nova economia digital: indivíduos e empresas criam riqueza, aplicando conhecimento e esforço às áreas de produção, agricultura e serviços. Segundo Tapscott (1997), na fronteira digital dessa economia, estão mudando os participantes, a dinâmica, as regras, as exigências de sobrevivência e o sucesso.

Esta dimensão é impulsionada pela conectividade, oportunidade sem paralelo para a comunicação, colaboração, compartilhamento de recursos e acesso à informação e à quebra das barreiras de distância e tempo. Este momento tem sido denominado a era digital. Para Vassos (1997) o rápido avanço do poder da computação e a abertura comercial da Internet trouxeram oportunidades tanto para as pequenas como para as grandes empresas. O mercado já começava a exigir que as organizações procurassem cada vez mais a diferenciação e a inovação. O compartilhamento de informações, não só local, mas principalmente de forma global ou mundial, torna-se imprescindível para a sobrevivência num mercado muito mais competitivo que o cenário anterior. Detecta-se então o fim das linhas demarcatórias tradicionais do comércio e, conseqüentemente, podendo ocorrer uma ascensão das empresas que atuam virtualmente no marketspace, o mercado na Internet.

A tecnologia de informação (TI) tem crescido em uso e desenvolvimento de duas formas básicas: (1) como resultado do aumento da complexidade relativa à informação nas empresas; e (2) possibilitando processos, atividades, produtos e serviços, até então inviáveis com as tecnologias anteriores, constituindo-se em uma difusão desencadeada pelos produtores de equipamentos e sistemas, por criarem necessidades e usos de seus produtos (Ramos, 1998). Com a crescente evolução da TI, o que era apenas uma função de suporte às tarefas administrativas, constitui hoje um componente estratégico de maior importância (Meirelles, 1992). Referindo-se a esse crescimento, Dern (apud Ramos, 1998) afirma que muitas organizações necessitam do acesso à Internet, principalmente porque uma conexão com ela pode reduzir drasticamente o custo de acesso às informações e melhorar significativamente o desempenho operacional, no concernente a serviços de informação e comunicação.

No campo das transações comerciais e financeiras, trocas de documentos entre os diversos envolvidos (fornecedores, clientes, parceiros), mediante fax, avisos postais e malotes, estão sendo crescentemente substituídas por operações 
online, via computador, seja pelo intercâmbio eletrônico de dados (EDI), seja pela utilização da Web, que se denomina WebDI. Esta modalidade de fazer negócios, com base na Web, é o que se pode chamar de comércio eletrônico, transacionado em nível de mercado eletrônico (e-market), envolvendo empresa a empresa (business-to-business) ou da empresa para o cliente (business to consumer).

Segundo definição pioneira de Bakos (apud Soares e Hoppen, 1998), o mercado eletrônico é o resultado de sistemas de informações que vão além das fronteiras das empresas, que põem em contato compradores e vendedores, via integração eletrônica. Algumas de suas características são a interatividade, a onipresença, a facilidade de acesso à informação e o baixo custo da transação.

Cabe destacar que, desde o aparecimento da Internet, o EDI, que até então tradicionalmente foi associado com comércio eletrônico, arrefeceu seu crescimento. Atualmente, a maioria das estratégias de comércio eletrônico estão baseadas em soluções tecnológicas de Internet, tendo alguns autores denominado este movimento de comércio baseado na Internet ou Internet commerce, definido como "a compra e a venda de informações, produtos e serviços, ou qualquer negócio transacionado entre duas empresas ou entre uma empresa e seus clientes, tendo como suporte os serviços da Internet” (Mougayar, 1998).

No caso das transações bancárias, com base em TI, os sistemas eletrônicos de padronização de documentos pretendem melhorar a eficácia, eliminar o alto custo de tarefas rotineiras nas agências. Pela adição de valor nos processos realizados por grupos interorganizacionais, permitem que os computadores troquem informações entre si, dispensando a digitação e a manipulação de dados, tornando mais segura e rápida a transação. Via integração digital, as redes armazenam, atualizam e distribuem documentos digitais. A segurança do acesso às informações pode ser feita, por exemplo, por meio da autenticação por assinatura eletrônica, uma senha que o usuário digita na página do banco, sem necessidade de carimbo, autenticação mecânica e/ou assinatura de papéis, devido aos softwares de criptografia.

Realizar transações bancárias é apenas mais um tipo de transação no universo quase infinito de possibilidades de fazer negócios pela Web. Projeções da empresa de pesquisas Forrester Research indicam que os negócios online deverão chegar a US\$1,3 trilhões em 2003. Reforçando essa previsão, uma pesquisa da Ziff-Davis Internet Trak aponta que a compra de bens e serviços online vai movimentar 17 bilhões de transações por ano até 2005 (Sun Network, 1999). O que ocorre no Brasil tende a ser um reflexo do que acontece em todo o mundo. 


\section{A Internet nos Negócios Bancários}

Segundo Albertin (1998), o setor bancário continua sendo considerado como um dos que mais investem em TI, que causa redução de custos e considerável vantagem competitiva. Assim, seja pelo seu novo ambiente, seja por força dos concorrentes, o setor bancário é um dos mais afetados pela nova realidade do comércio eletrônico. Esta situação tem exigido grande esforço para a assimilação e utilização das TI referentes a comércio eletrônico, na sua operacionalização e na sua estratégia competitiva.

De maneira geral, os bancos que oferecem serviços via Internet mantêm um padrão relativamente semelhante de atividades oferecidas, tais como consultas de saldos e extratos, transações entre contas, pagamento de faturas, entre tantas outras. Os que entram inicialmente na automação via rede oferecem as mesmas opções; quando apresentam uma inovação, esta é logo seguida. Isto pode ser creditado ao fato de que é mais fácil praticar a inteligência competitiva, pesquisando pela Internet; no entanto pode-se destacar que há distinções entre os grandes bancos que primeiro investiram intensamente, como o Bradesco, o Itaú e, seguindo de perto, o Banco do Brasil (BB) e a Caixa Econômica Federal (CEF).

Numa restrospectiva histórica, há apenas 4 anos o panorama nacional dos bancos mostrava-se incipiente. O CCF, por exemplo, um banco até hoje desconhecido, existe no país há 30 anos e na Internet desde maio de 1996. Naquele momento se definia como um banco que apostava apenas no repasse de informações via Internet aos seus clientes, por meio de correio eletrônico ou de recursos visuais, e evitava envolver-se em negócios por meio da rede. No mesmo período, em outros bancos, como o Itaú e o HSBC, a filosofia era usar a internet como canal alternativo de comunicação, sobretudo para quem estava fora do país. Em ambos, a estratégia era manter a expansão, para oferecer no futuro as mesmas facilidades disponíveis na Web (Internet World, 1997).

Por outro lado, o Bradesco, por exemplo, tornou-se a primeira instituição financeira no Brasil a usar a Internet para oferecer serviços bancários. Em 1997 já atingia 1,5 milhão de acessos por mês, tendo sido o primeiro a disponibilizar aos clientes um canal para conferência de saldos, extratos, transferências, tendo ainda como estratégia de serviços incentivar o uso do Internet banking, oferecendo financiamentos de microcomputadores e convênios com provedores da rede. Foi também inovador em oferecer o acesso gratuito à Internet a seus correntistas. Já o Banco do Brasil oferecia serviços similares, porém restritos a um públicoalvo, como funcionários de empresas. Por exemplo, na Universidade Federal do Rio de Janeiro (UFRJ), através de uma parceria entre o núcleo de computação da universidade e o banco, todos os que eram correntistas poderiam conferir seu 
extrato, mas pagamentos, aplicações e resgates ainda não estavam disponíveis naquele momento. No ano seguinte nascia o serviço de homebanking pela Internet.

Numa perspectiva mais atual, observa-se um crescimento de transações bancárias pela Internet, reflexo do aumento da confiabilidade por parte dos usuários. Cada vez mais correntistas acessam os diversos serviços de Internet banking existentes. No Bradesco, através do BradescoNet, 350.000 de seus 440.000 clientes online usam os serviços pela Internet, em vez do serviço original do próprio banco, com crescimento de $12 \%$ ao mês, o que representa mais de $7 \%$ do total das transações (Gates, 1999). No Unibanco, além de transações, abrem-se mais de 1.000 contas por dia. No Banco do Brasil 5,5\% das transações já são através do personal banking (Infoexame, 1998).

Os bancos têm investido bastante para se atualizar tecnologicamente. Em 1998, quatro grandes bancos (BB, CEF, Itaú e Bradesco) investiram quase US\$1,3 bilhão em tecnologia de informação, sendo previsto cerca de US\$1 bilhão para o ano de 1999. O BB, por exemplo, vem investindo em infra-estrutura e tecnologia nos últimos quatro anos, algo em torno de $\mathrm{R} \$ 1$ bilhão, considerado o maior investimento em tecnologia de processamento de dados e automação de todo o setor bancário brasileiro (Banco do Brasil, 1998). Tudo isso demonstra que a tecnologia da informação é de suma importância para as instituições bancárias. Novos produtos e serviços, com o formato certo para a utilização via computador, estão sendo produzidos pelos bancos, como forma de se manter no mercado, captando recursos e gerando receitas.

De acordo com Gates (1999), os serviços bancários online foram mais rapidamente difundidos no Brasil do que em qualquer outro país. Em 1997, os banqueiros gastaram 230 milhões em tecnologia e automação bancária, o que corresponde a $28 \%$ do lucro daquele ano. O Banco do Brasil, no mesmo ano, investiu no setor 261,8 milhões (Exame, 1998). As instituições financeiras passam a adequar os seus produtos e serviços, com vistas a efetivar a sua comercialização eletrônica, como por exemplo, as linhas de financiamento direto aos consumidores, os CDCs do Banco do Brasil, que podem ser formalizados via Internet ou terminais de auto-atendimento (Banco do Brasil, 1999).

\section{A Tendência do Auto-Serviço Bancário Online}

Para Clark (1998) duas tendências de marketing têm aparecido na world wide web nos últimos anos. Uma delas mostra a criação de empresas virtuais, ou seja, empreendimentos lucrativos e autônomos que existem somente na Internet. $\mathrm{Na}$ outra, aparecem as empresas que usam a Web como complemento do marketing 
tradicional, oferecendo benefícios adicionais aos clientes e estabelecendo relacionamento com eles, freqüentemente fazendo parte da estratégia geral da marca.

A criação de valor da economia atual está crescentemente relacionada aos intangíveis. Os administradores que não têm ainda uma linguagem sistemática para examinar esses processos ficarão inevitavelmente à margem. Assim, as organizações buscam a hegemonia da tecnologia, oferecendo cada vez mais serviços mais acessíveis, de qualidade superior e de custo baixo. Inevitavelmente, a tendência ao auto-serviço é uma conseqüência dessa evolução, transformandose na tônica do momento, o ponto crucial que as empresas procuram alcançar.

No caso dos bancos, o auto-serviço enriquece a produtividade das tarefas dos escriturários em serviços e contribui para alcançar ganhos de escala pela padronização e técnicas de produção em massa. Uma característica relevante serve para reforçar a lógica inerente da economia de serviços: integrar-se com o processo do cliente, adaptar-se crescentemente ao complexo relacionamento coprodutivo. As organizações passam a enxergar os seus consumidores não só como usuários ou clientes, mas como co-produtores dos seus serviços, pois parte do que o indivíduo observa como produto da empresa de serviços consiste em quanto e de que maneira ele tem de participar da prestação do serviço, bem como quais problemas e satisfações estão envolvidos nesse processo.

Para que tudo transcorra bem, as empresas partem para a definição do pacote de valor, que Albrecht (1993) define como sendo uma combinação de coisas e experiências que criam uma percepção total do valor recebido. Para tornar o cliente co-produtivo, a persuasão mais importante é provavelmente sobre o custo: ele participa se houver economia ou se puder chegar a uma relação preço/ qualidade mais favorável. Além disso, a participação do processo pode ser uma experiência interessante ou mesmo estimulante, pois ele pode não querer ficar para trás das tecnologias modernas. Como último recurso, as organizações passam a qualificar os seus usuários, treinando-os e tornando-os mais eficazes, com bom retorno para a empresa.

Nas aplicações bancárias, o auto-serviço online faz ao mesmo tempo sua parte da entrega do produto ao cliente, como também dá a este a oportunidade de vivenciar a experiência do serviço. A velocidade da entrega e a interação online possibilitam que a Internet transforme efetivamente os produtos em serviços. Seguindo esta linha, a teoria do momento de verdade, relativa à qualidade de serviços preconizada por Normann (1993), deve ser levada em consideração quando se avalia a prestação de serviços bancários pela Internet.

Diante do exposto, passa-se a descrever quais aspectos foram utilizados no presente estudo de comércio eletrônico bancário, apresentando seus resultados 
mediante duas formas distintas e complementares. O primeiro suporte refere-se à análise dos websites do Banco do Brasil e de seus principais competidores. As características marca na Internet, linguagem/versão do site, mecanismos de busca e ajuda, possibilidade de canal de comunicação, divulgação de negócios e marketing, notícias e informativos do banco, dados institucionais e acesso para pessoas jurídicas foram selecionadas.

No segundo suporte, houve a pesquisa com os clientes, em que foram levantados alguns aspectos com relação à satisfação do usuário do personal banking do $\mathrm{BB}$, por meio do seu site na Internet, escolhendo-se estas questões: forma de comunicação com os clientes para resolução de problemas e dúvidas, solução do sistema de segurança e privacidade, atributos desejáveis de qualidade do serviço, adequação da qualifícação e envolvimento dos funcionários com relação às tecnologias, e utilização e conhecimento dos sites dos concorrentes como referenciais para o questionário.

\section{Caracterização do Caso do Banco do Brasil}

O Banco do Brasil conta com mais de 4.500 pontos de atendimento em todo o país e cerca de 37 agências e 13 escritórios de representação espalhados pelo mundo inteiro. Acompanhando o avanço tecnológico exigido pelo mercado, existem cerca de 6.400 terminais multifuncionais de auto-serviço e 9.500 terminais de consulta (extrato) distribuídos nas principais agências ou instalados em locais estratégicos nas grandes cidades.

O número de transações diárias, via computador, quadruplicou, passando de 8 milhões em 1995, para 35 milhões em 1997, em 68.000 microcomputadores ligados em rede. O referido banco possuía apenas 3 salas de auto-atendimento em 1994, possui hoje 580. O BB instalou 22.000 terminais (Informativo, 1998) de auto-atendimento, uma das maiores redes de auto-serviços do país. Do lado dos clientes, 300.000 aderiram ao $\mathrm{BB}$ personal banking, em um ano. Quanto à presença do Banco do Brasil no Estado do Rio Grande do Norte, são apresentados os seguintes dados: existem 54 agências, concentrando 13 em Natal, capital do Estado, totalizando cerca de 500 terminais instalados. O BB investe no mercado do Rio Grande do Norte algo em torno de R \$250 milhões, fomentando em quase $50 \%$ a sua economia (Tribuna do Norte, 1998), o que dá a medida da sua importância para o Estado.

Do ponto de vista organizacional, cada agência da empresa possui autonomia em decisões antes limitadas a escalões superiores, reflexo de um movimento 
recente de reestruturação global para se tornar mais ágil e competitiva. As agências inserem-se no grupo das unidades estratégicas de negócios do banco, com a área funcional de distribuição. Assim, a agência aqui estudada é denominada UEN/Distribuição/Agência Natal Shopping Center, e situa-se em Natal, RN. Como o próprio nome diz, esta agência vem atuando com exclusividade nas dependências de um shopping center, o maior da cidade, fomentando o mercado dos lojistas tanto internamente como atingindo áreas circunvizinhas. Suas instalações cumprem a padronização do seu atendimento lançado pela cúpula da empresa, possuem instalados terminais multifuncionais de última geração, layout atual, que acompanha a modernização do setor; contam com a presença de 30 funcionários.

\section{O BB Internet Banking}

O BB Internet banking pode ser caracterizado como um conjunto de soluções de auto-atendimento desenvolvidas para oferecer aos clientes do banco um atendimento rápido, seguro e com total disponibilidade de horário e formas de acesso via Internet (SISBB, 1998). Esta modalidade insere-se dentro de um conjunto maior de aplicativos, que conta com estrutura de produtos e serviços informatizados, utilizando alta tecnologia, ampla rede de distribuição e diversidade de canais, como o BB personal banking.

Mais especificamente, o home banking/Internet banking disponibiliza produtos e serviços mediante interligação do microcomputador do cliente aos computadores do banco, utilizando aplicativo desenvolvido para ambiente de microcomputador Microsoft Windows ou via endereço do BB na Internet (http:// www.bancobrasil.com.br/personal).

Este serviço de Internet banking, ou o Banco na Internet do Banco do Brasil, objeto deste estudo, é disponibilizado de três formas: (1) pela Internet, com acesso através do endereço do banco por intermédio de um provedor de Internet (particular ou gratuito) e com o auxílio de um navegador (browser); (2) via aplicativo existente nos sistemas operacionais da Microsoft Windows, a rede dial-up que, corretamente configurada, permite o acesso sem a necessidade de um provedor; e (3) por EDI, exclusivamente para empresas de grande porte e de volume de negócios compatível com a necessidade da sua instalação, o LDBB.

As principais vantagens que justificam o investimento em tecnologia são: descongestionar $\mathrm{o}$ atendimento, minimizando ao máximo a ida do cliente às agências; reduzir custos operacionais; associar a imagem de banco moderno e automatizado; e aumentar a receita de tarifa, que é repassada integralmente para as agências. Os requisitos apontados também como vantagens pelo banco são: agi- 
lidade, conveniência, privacidade (pela não interveniência humana de terceiros) e segurança, desde que sejam observados os padrões de segurança aplicados ao sistema bancário. Outro aspecto é a possibilidade de realizar várias operações em um mesmo ambiente, pela simplificação e integração.

\section{Metodologia da Pesquisa}

A primeira parte da pesquisa refere-se à abordagem situacional dos serviços bancários eletrônicos dos principais bancos brasileiros, acessados pela Internet, colhendo dados dos principais sites bancários na Internet, na busca do diferencial competitivo no mercado, de acordo com a visão de benchmarking.

Com relação à segunda parte da pesquisa, a fim de buscar maior consistência dos dados descritivos abordados, optou-se por incluir também uma pesquisa de campo, de natureza de estudo de caso exploratório, entrevistando clientes do BB que se utilizam de serviços bancários pela Internet.

Para composição da amostra destes clientes, foi consultada a agência do estudo de caso, em que se verificou que havia 144 usuários cadastrados ao BB personal banking, modalidade que possibilita, entre outras opções, o acesso ao BB a partir da sua própria residência ou em qualquer lugar onde possa acessar a Internet; no entanto um dificultador para a pesquisa foi obter do BB a identificação daqueles que efetivamente acessam aquele serviço. Para contornar este problema, usaramse dados que o próprio Banco do Brasil divulgou, em meio interno de comunicação (SIBB, 1999), de que $74 \%$ das suas transações são efetuadas via terminal de auto-atendimento, e somente 5,5\% pela Internet. Para se ter uma idéia, numa proporção estadual, dos 4.078 usuários cadastrados no home banking/personal banking, apenas 225 estariam realmente acessando-o, de acordo com a estatística do banco. A literatura também confirma esta estimativa de uso da Internet por parte dos correntistas, ainda situada na literatura em torno de 5\% (Gates, 1999), apesar dos indícios de que o uso poderá aumentar entre os clientes de bancos.

Numa correspondência com o locus da pesquisa, dos 144 contratos da agência do shopping center, aproximadamente 8 clientes seriam usuários do serviço; mas decidiu-se aplicar o questionário para 15 clientes, quase o dobro do que seria estatisticamente esperado, pois observou-se que naquela agência havia um número maior de clientes que se utilizavam do Internet banking, podendo isto ser creditado ao fato de estar localizado em bairro de renda mais elevada que a média local, aproximando-se do perfil de cliente mais próximo do usuário da Internet (IBOPE, 1998), em torno de 8 a 10\% do mercado consumidor. 
A seleção destes clientes/usuários do aplicativo foi não-aleatória, consistindo em uma abordagem direta de clientes que compareciam nesta agência. A utilização da amostra por acessibilidade foi motivada em virtude de a empresa não possuir uma listagem de quem realmente utiliza o home banking/personal banking, como mencionado, mas também por razões de simplicidade e custo e pela natureza mais exploratória da questão de pesquisa.

Para a coleta de dados, foi utilizado um questionário com perguntas abertas e fechadas, com opções variadas ou em forma de escala, todas direcionadas aos objetivos do estudo e com ele identificadas. Para dar suporte à elaboração do questionário, foi realizada uma pesquisa documental de levantamento de textos relacionados ao assunto, além de temas correlatos; pesquisa de sites de instituições financeiras, e seleção de vídeos informativos produzidos pela própria empresa. Após a coleta de dados, realizada durante a primeira quinzena de fevereiro de 1999 , foi feita a tabulação e a análise dos questionários, utilizando o método de análise de conteúdo, quando procedente.

\section{Avaliação dos Negócios Bancários pela Internet: Resultados da Pesquisa}

Na discussão e análise dos resultados obtidos, esta seção é dividida em duas partes. Na primeira, são descritos e comparados os diversos serviços disponíveis no comércio eletrônico bancário. No segundo momento, são apresentados os indicadores da visão dos clientes do $\mathrm{BB}$, em relação à utilização do personal banking Internet.

\section{Análise Comparativa do Internet Banking do BB com Relação aos Websites}

Apresenta-se, a seguir, o resultado da pesquisa realizada nos endereços na Internet relacionados no mês de janeiro de 1999: Banco do Brasil, Itaú, Bradesco, HSBC, Unibanco e Banco Real ${ }^{(4)}$. Após o processo de pesquisa dos websites, foram mapeados os principais aspectos presentes, tendo em vista uma abordagem competitiva do que as instituições financeiras oferecem de atrativo aos usuários em potencial da Internet. No Quadro 1 apresenta-se o resultado comparativo destes aspectos. De forma geral, observa-se que as páginas da Internet consultadas apresentam características praticamente idênticas, o que mostra a sintonia daqueles que procuram a liderança do mercado, mudando características de design, basicamente. 


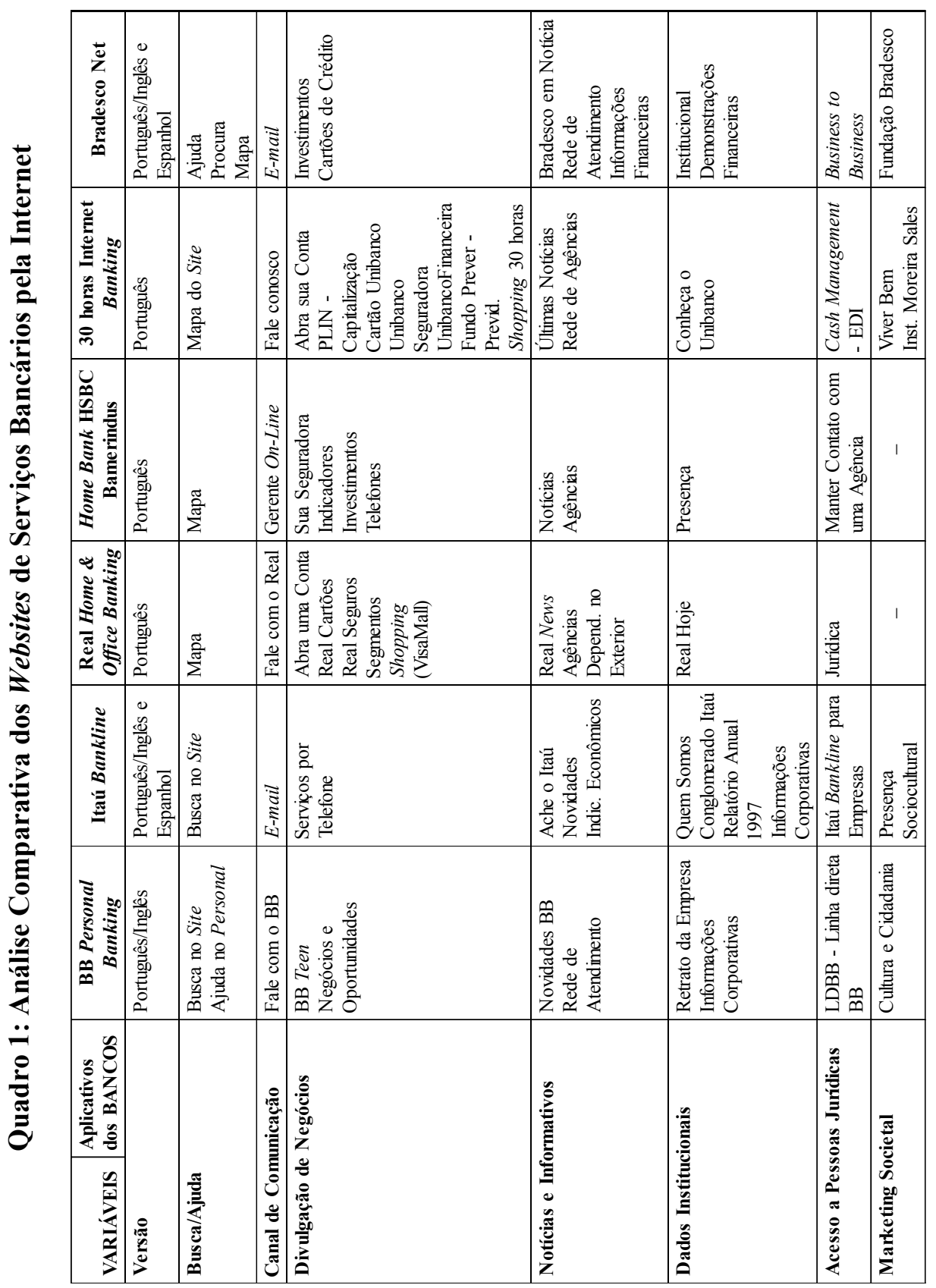


Com relação aos aspectos diferenciadores, cada instituição possui marca própria em relação ao seu banco na Internet; entretanto expressões como Internet banking e home banking tornaram-se genéricas em seu meio.

Como diferencial competitivo e de olho no usuário do exterior, até mesmo pelo fato de algumas atuarem nesse mercado, alguns sites têm versões apresentadas em outras línguas estrangeiras. O Bradesco e o Itaú divulgam o seu Internet banking, em inglês, espanhol e claro, em português. O Banco do Brasil apresenta, além da língua pátria, somente a versão em inglês. Pelo fato de o BB possuir penetração no exterior, deveria apresentar versões em outras línguas, pelo menos em espanhol. Noutras instituições, por exemplo o Banco Real, surpreende o fato de haver presença fora do país, e apresentar o site apenas em português. Igualmente ocorre com o conglomerado HSBC, que apresenta na sua home page uma versão em inglês do HSBC Group, com pouca atratividade. Por último, o Unibanco, sem divulgação de agências no exterior, apresenta sua versão em português.

Em matéria de ajuda online, ou busca de informações no próprio site, todos apresentam ícones de acesso. Ocorre também que outros processos de ajuda (help) não são visualizados de pronto, como, por exemplo, no Banco do Brasil que, dentro do personal banking, oferece uma ajuda, que é o serviço BB-Responde. Além disso, apresenta uma busca no site ineficiente.

O canal de comunicação é também enfatizado pelas instituições. Alguns se utilizam desse canal, denominando títulos que possuem valor atrativo de marketing. O Gerente On-Line do HSBC, por exemplo, soa diferente dos demais. Entre os bancos abordados, apenas o Itaú não apresenta este ícone, sendo que, em pesquisa mais apurada, constatou-se a existência de um correio eletrônico disponível para os cadastrados no Itaú Bankline. O Fale com o Banco do Brasil, após acessado, dá ao usuário duas opções: registrar comunicado para o BBResponde ou para o webmaster, gerenciador das páginas na Internet. O Bradesco também tem no e-mail a forma apresentada para o cliente se comunicar com a empresa.

Sendo uma mídia que tem crescido assustadoramente, a Internet tem sido o meio de divulgação de novos negócios e marketing mais rápido e eficiente dos últimos tempos. Assim, as instituições financeiras oferecem páginas de Web atrativas aos seus usuários. Esses apelos publicitários, às vezes, atrapalham mais que beneficiam. Durante o estudo, foi observado que a home page do Banco Real, por exemplo, tem uma forte estrutura de imagens, dificultando o seu carregamento. Já em matéria de marketing, utiliza uma estratégia segmentada de atuação, oferecendo vantagens para cada tipo de profissão: dentista, Forças Armadas, estudantes etc. Outro aspecto relevante, é a preocupação desse banco em 
manter ícones de serviços como o Real Cartões e o Real Seguros, visando a uma maior divulgação, fugindo um pouco do tradicional Produtos e Serviços. Outra novidade são os links para Shopping Virtual, caso do Banco Real e do Unibanco. Este último disponibiliza informações mais detalhadas sobre produtos financeiros. Os demais bancos utilizam uma estrutura mais leve. O Itaú faz publicidade dos seus serviços por telefone. O HSBC e o Bradesco incitam os clientes ao ícone de investimento, repassando dicas do mercado e dos seus produtos. Mantendo uma estratégia de inovação, o Bradesco lança um produto novo, o home banking para deficientes visuais. Por sua vez, o Banco do Brasil apresenta o BB Teen, um produto exclusivo para adolescentes a partir de treze anos.

Procurando deixar os seus clientes sintonizados com o que ocorre de importante com a empresa, as instituições divulgam informativos e notícias de interesse do público, em relação a sua atuação no mercado. Outra preocupação é divulgar a relação dos milhares de pontos de atendimento do país. Um diferencial competitivo, que não foi localizado no Banco do Brasil, foi a divulgação de indicadores financeiros ou dos seus vários produtos de investimentos.

Confirmando uma tendência do marketing, via rede, para empresas físicas, as instituições financeiras divulgam, por meio da sua home page, seus dados institucionais. Demonstrações financeiras, um pouco de história e atuações no mercado são algumas das formas de procurar estreitar o relacionamento dos bancos com os seus usuários.

Outro fator diferencial competitivo e mercadológico muito importante é o acesso de pessoas jurídicas ao home banking. Em função do volume de negócios que podem ser oferecidos, muitos serviços, principalmente os que requerem transmissões intensas de dados, fazem com que isso seja dificultado através da Internet. Dessa forma, foi observado no levantamento que as instituições possuem aplicativos especiais para comutação de dados, através de EDI, ou troca de dados micro a micro. O Banco do Brasil tem a sua solução de EDI; o Bradesco oferece o Business to Business; o Unibanco o Cash Management; o Itaú apresenta o Bankline para Empresas. O Banco Real e o HSBC possuem a mesma facilidade, porém não tão bem esclarecida como os demais.

Num momento em que a sociedade busca cada vez mais a identidade cultural e seus direitos sociais, alguns bancos também apresentam um relativo compromisso com os aspectos sociais e culturais. A maioria das instituições abordadas no estudo demonstraram isto nos seus websites. Assim, procuram divulgar, na forma de marketing societal, suas ações na área. O Unibanco atua no incentivo ao teatro, cinema e arte em geral. O Bradesco atua principalmente na educação e capacitação de jovens e adultos. O Itaú possui projetos ligados à saúde e à educação, nas diversas comunidades onde está presente. Por último, o Banco do 
Brasil lançou, desde 1993, o BB Educar: voluntários do próprio corpo funcional atuam junto às comunidades, onde a empresa tem presença. Existe também o comitê de cidadania contra a miséria e contra a fome. Apenas dois bancos não divulgaram suas ações nesta área: o HSBC e o Banco Real.

Do quadro exposto, infere-se que os serviços via Internet das instituições financeiras parecem realmente sintonizados com a concorrência, uma de olho na outra, apresentando soluções e atrativos semelhantes. Tal fato pode ser explicado por dois aspectos: o desenvolvimento das páginas ser efetuado por empresas especializadas, assemelhando assim as contruções de seus websites, como também pela grande vitrine que é a própria Internet, propiciando um benchmarking mais evidente e transparente.

\section{Análise Comparativa do Internet Banking do BB na Visão dos Clientes}

Em função das respostas obtidas com o questionário aplicado na agência, nesta seção serão apresentados os resultados obtidos da visão dos clientes com relação à utilização do Internet Banking do BB. As variáveis utilizadas na análise foram as seguintes: forma de comunicação com os clientes para resolução de problemas e dúvidas, solução do sistema de segurança e privacidade, atributos desejáveis de qualidade do serviço, adequação da qualificação e envolvimento dos funcionários com relação às tecnologias, e por fim, utilização e conhecimento dos sites dos concorrentes.

De acordo com a análise efetuada, com relação à forma de comunicação BBResponde, $73,3 \%$ dos entrevistados afirmaram que já utilizaram o serviço, reflexo do perfil exigente dos clientes e do nível de conhecimento da informática que deve ter o usuário. Quanto ao grau de satisfação, 54,5\% acham o atendimento bom, mas não houve assinalação de ótimo. O total dos níveis de ruim a péssimo somou $27 \%$, uma parcela elevada de descontentes. Para um aplicativo que está sendo certificado com a ISO 9002, é um item que deveria preocupar mais a empresa.

No tópico de investigação da segurança em transacionar pela Internet, 73,3\% das respostas ficaram entre os níveis bom e ótimo, o que possivelmente indica uma tendência de que os usuários estão ficando cada vez menos resistentes em relação à segurança do comércio eletrônico atual. Em relação aos sistemas eletrônicos de pagamentos, $66,6 \%$ dos usuários responderam que estão satisfeitos.

Quanto aos atributos de qualidade do site de comércio eletrônico, foram escolhidos alguns aspectos básicos que devem ser monitorados pela empresa, operações que marcam a percepção do cliente. Nesta questão, os clientes davam notas de 0 a 15 para estritamente importante; 16 a 30 para muito importante; 
31 a 45 para média importância; 46 a 60 para pouca importância; 61 e 75 para nenhuma importância, naqueles atributos de qualidade do serviço. O Quadro 2 apresenta os resultados tabulados.

\section{Quadro 2: Atributos de Qualidade mais Importantes}

\begin{tabular}{|l|c|c|}
\hline A SPEC TOS & $\begin{array}{c}\text { N ÍV E L D E } \\
\text { IM PO R T Â N C IA }\end{array}$ & PO N T U A Ç Ã O \\
\hline R apidez no carregam ento & M uito ím portante & 22 \\
\hline F uncionalid ade das transações & M uito ím portante & 26 \\
\hline Info rm ações de produtos e serviços & M uito ím portante & 29 \\
\hline A juda on line & M édia ím portância & 35 \\
\hline C analaberto com o cliente & M édia ím portância & 41 \\
\hline D ados e struturais da organização & S em im portância & 63 \\
\hline N otícias da em presa & S em im portância & 64 \\
\hline V isualatratío & S em im portância & 64 \\
\hline
\end{tabular}

Como se pode observar, os aspectos tecnológicos da rede, como o carregamento da página e funcionalidade das transações são os primeiros atributos de qualidade na percepção dos clientes, considerados essenciais para a relação satisfatória com o serviço bancário pela Internet. As informações de produtos e serviços também foram consideradas críticas, visto que nem todos possuem conhecimentos sobre os mecanismos intrínsecos do próprio serviço e necessitam de esclarecimentos sobre condições e restrições. Desta forma, no momento em que a empresa é ativada via Internet, as linhas ou os servidores têm de ser eficientes, para que a conexão imediata ocorra sem problemas; o carregamento da página, em outro momento, tem de ser rápido, eficiente; o seu conteúdo deve atender às necessidades do usuário.

No nível de média importância, estão a ajuda online e o canal de comunicação, indicando que o cliente do BB não tem tanta necessidade de se comunicar, merecendo maior investigação as razões do fato.

Os itens relacionados ao marketing institucional não foram absolutamente considerados importantes. As divulgações de notícias da própria empresa e o seus dados estruturais não são atributos de diferencial de qualidade para estes clientes. Pode-se explicar, neste caso, que como se trata de instituições sólidas e com muitos anos de atuação no mercado, os clientes não têm necessidade de pesqui- 
sar ou buscar informações sobre estas em seu site. Um dado relevante é o fato do atributo de visual atrativo ter ficado com a pior pontuação. Parece indicar que os usuários não levam em consideração esse detalhe, pelo menos para páginas desta natureza. Pesquisas mais detalhadas sobre o papel do design em produtos de Internet poderiam investigar melhor este aspecto, aqui pouco esclarecedor.

Quanto à adequação da qualificação e integração dos funcionários às mudanças tecnológicas do $\mathrm{BB}$, embora os níveis ruim e péssimo não tenham sido indicados, tivemos $46,6 \%$ estacionados no nível regular, indicativo de que algo precisa melhorar neste quesito. Provavelmente, isto ocorre devido à velocidade das mudanças no mercado, e que não estão sendo convenientemente acompanhadas pelos funcionários, como resultado de uma estratégia de treinamento e educação tecnológica merecedoras de maior cuidado e empenho.

Em relação ao aspecto da concorrência, apenas 13,3\% dos entrevistados utilizam os serviços de outras instituições, demonstrando fidelidade significativa com a empresa. Por outro lado, quando foi perguntado se os sites de outros bancos estão sendo por eles visitados, houve $46,6 \%$ de indicações, o que demonstra que os usuários não estão parados no tempo; estão sintonizando outras instituições, possivelmente até mesmo comparando-as quanto aos serviços, para uma futura mudança de relacionamento. Entre os outros sites mais citados estão: o Bradesco, pela sua funcionalidade e rapidez, e a CEF, pela rapidez e detalhamento dos serviços.

\section{RECOMENDAÇóES}

Com a realização da abordagem situacional da concorrência em Internet banking, o BB pode traçar um perfil do usuário local, e utilizar esses dados como base para outras pesquisas. Com a identificação das barreiras a superar e sugestões de melhorias, o Banco do Brasil também poderá montar uma estratégia em face da concorrência, no sentido de melhorar sua posição competitiva. Para tanto, os seguintes aspectos poderiam ser observados.

- Implantar as opções de atualização de cadastro e solicitação de talonários de cheques.

- Verificar o funcionamento da tecnologia de agendamento de aplicações e resgates em fundos de investimentos, bem como resgates de poupança, aprimorando-os de forma a superar os concorrentes. 
- Rever a posição quanto às tarifas cobradas aos clientes, por sua adesão ao serviço pela Internet, buscando taxas mais competitivas.

. Integrar o site do BB com o mundo, acrescentando mais uma versão de lingua estrangeira, o espanhol, igualando-se à concorrência.

. Informar as taxas das opções de investimentos da empresa e os indicadores econômicos mais comums ao dia-a-dia dos clientes.

- Se o BB-Responde é certificado com a ISO 9002, deve ser divulgado no site; entretanto mais rigor deve ser destinado a esse canal. A resposta pode estar sendo dada tempestivamente, mas a satisfação do cliente pode não estar sendo atingida efetivamente.

. Os concorrentes apresentam versões DEMO de acesso aos seus home banking; assim, no momento em que os consumidores se tornam mais exigentes, e comparam os produtos oferecidos no mercado, as organizações devem acompanhar as inovações, mas também se tornarem inovadoras.

Quanto à abordagem dos clientes, muitas sugestões de melhoria foram compiladas pela amostra da pesquisa. Relacionam-se a seguir aquelas que correspondiam efetivamente em um ponto de melhoria.

- Manter a página com um nível de carregamento atual melhor, incrementar a funcionalidade das suas operações, atributos de qualidade que mais atraem os clientes.

- A configuração da rede dial-up, que permite que os usuários possam acessar o BB sem necessitar de provedor da Internet, não foi bem assimilada pelos clientes, devendo-se buscar uma forma alternativa de instruí-los, além da distribuída em folder, e obter maior publicidade.

. Para incrementar o auto-serviço, deve haver um incentivo de financiamentos de microcomputadores.

. Incentivar mais o corpo funcional, inserindo temas no programa de profissionalização direcionados ao acompanhamento da tecnologia para proporcionar melhor atendimento ao cliente.

. Criação de uma sessão no site mais direcionada às perguntas mais freqüentemente respondidas (FAQ's). Acredita-se que muitos problemas seriam resolvidos desta forma.

- Na opção de financiamentos, deve ser implantada uma maneira de simular o seu empréstimo, pois assim o cliente poderá visualizar e mellhor adequar a sua capacidade de pagamento. 
. O acesso a extratos e saldos nunca deveria ficar indisponibilizado, mesmo que para isso haja informações de que o saldo esteja sujeito a atualizações.

. Utilizar a Internet para divulgação dos sorteios do OuroCap.

- Verificar a possibilidade de se implantar contra-ordem, para cheques, via Internet.

\section{ConClusÃo}

A Internet, indo além da tecnologia, é toda uma nova área de inovação e reinvenção na forma de fazer negócio, como o caso do comércio eletrônico. Não se deve perder de vista que, cada dia, novas formas de utilização dessa TI são criadas e devem ser assimiladas rapidamente. Tanto as organizações como os seus funcionários devem estar em sintonia direta com isso, sob risco de perda da competitividade do mercado. A literatura de negócios e pesquisas mostra que esta é a tendência mundial: a corrida da Internet, a expansão das formas de autoserviços.

O estudo mercadológico mostra que o Banco do Brasil se tem mostrado atento às mudanças desse filão e parece acompanhar a evolução do home banking; entretanto precisa responder mais velozmente para estar em condições de nivelar-se de igual para igual aos líderes em automação bancária do país, fazendo jus ao seu porte e importância no mercado como um todo. Comparando os produtos, serviços e informações constantes da página do Banco do Brasil na Internet em relação às demais instituições abordadas no estudo, concluímos que pequenos detalhes, se corrigidos, podem dar esta afirmação de que a empresa necessita.

A pesquisa de satisfação pode contribuir no sentido de dar à instituição a oportunidade de conhecer o perfil de seus usuários na região e comparar a resultados de outras. Alternativamente, poderá utilizar essa abordagem inicial para a formalização de outras estratégias. Foram recolhidas ainda algumas sugestões de melhorias, além da comparação dos ganhos obtidos e das barreiras a superar, listadas na seção anterior. Algumas são comprovadamente melhorias que deveriam ser implementadas. Outras dependem apenas de informações, que também podem ser solucionadas com as sugestões apresentadas pelo estudo.

A abordagem apresentada tem como característica limitante o fato de ser temporal e altamente mutável. No caso da Internet isto se torna ainda mais crítico, dado o enorme dinamismo deste canal e a velocidade com que se processa sua 
difusão no meio empresarial; todavia espera-se que este trabalho sirva como incentivo a outros acadêmicos, como forma de consulta, comparações e atualizações em estudos posteriores.

\section{Notas}

${ }^{1}$ Disponibilizado na URL: http://www.nua.ie/surveys/how_many_online/index.html.

${ }^{2}$ Acessado online na URL: http://www.nua.ie/surveys/how_many_online/s_america.html.

${ }^{3}$ Disponibilizado na URL: http://www.ibope.com.br.

${ }^{4}$ Banco do Brasil (www.bancodobrasil.com.br), Itaú (www.itau.com.br), Bradesco (www.bradesco.com.br), HSBC (www.hsbcbamerindus.com.br), Unibanco (www.unibanco.com.br) e Banco Real (www.bancoreal.com.br).

\section{REFERÊNCIAS BiBLIOGRÁFICAS}

\section{ALBERTIN, A. L.}

Comércio eletrônico : um estudo no setor bancário. In: XXII ENCONTRO ANUAL DA ANPAD (1998 : Foz do Iguaçu). Anais Eletrônicos... Foz do Iguaçu : ANPAD, 1998.

\section{ALBRECHT, K.}

A única coisa que importa : trazendo o poder do cliente para dentro da sua empresa. 2. ed. São Paulo : Atlas, 1993.

\section{BANCO DO BRASIL.}

Vídeo tecnologia. Banco do Brasil, 1998.
Sistema de informações internas do Banco do Brasil. Banco do Brasil, 1998.

Sistema de informações internas do Banco do Brasil. Banco do Brasil, 1999.

CLARK, B.

Negócios on-line. HSM Management, v. 8, p. 110-118, maio/jun. 1998.

DONOVAN, J. J.

The second industrial revolution : reinventing your business on the web. Englewood Cliffs, NJ : Prentice-Hall, 1997. 
DOWNES, L.;

MUI, C.

Unleashing the killer ap : digital strategies for market dominance. Boston, MA : Harvard Business School Press, 1998.

\section{EXAME.}

Reportagem de capa. 11 mar. 1998. p. 98-100.

IBOPE.

[online]. Disponível na Internet via WWW.URL : http:// www.ibope.com.br. Fev. 1999.

\section{INFO EXAME.}

A ascensão do consumo digital. ano 11, p. 96-100, jul. 1998.

\section{INTERNET WORLD.}

Inaugurando uma nova era. v. 2, n. 16, p. 45-49, jan. 1997.

MEIRELLES, F. S.

Informática : novas aplicações com microcomputadores. São Paulo : McGraw-Hill, 1992.

MOUGAYAR, W.

Opening digital markets : battle plans and business strategies for Internet commerce. 2. ed. New York : McGraw-Hilll, 1998.

\section{NORMANN, R.}

Administração de serviços : estratégia e liderança na empresa de serviços. São Paulo : Atlas, 1993.
RAMOS, A. S. M.

Tecnologia da informação para a gestão da qualidade. UFRN, 1998. apostila de curso de especialização em gestão da qualidade total.

SEYBOLD, P. B.

Customers.com : how to create a profitable business strategy for the Internet and beyond. New York: Radom House, 1998.

SOARES, R. O.;

HOPPEN, N.

Aspectos do uso da Internet pelas grandes empresas no Brasil : um estudo exploratório baseado em sites web. In: XXII ENCONTRO ANUAL DA ANPAD (1998 : Foz do Iguaçu). Anais Eletrônicos... Foz do Iguaçu : ANPAD, 1998.

SUN NETWORK.

We're the dot in.com. Revista da Sun Microsystems do Brasil, v. 8, n. 22, p. 22, ago. 1999.

TAPSCOTT, D.

Economia digital : promessa e perigo na era da inteligência em rede. São Paulo : Makron Books, 1997.

TRIBUNA DO NORTE.

Banco do Brasil : 190 anos servindo ao país. Natal, 19 out. 1998. Caderno especial. 
TV SENAC-SP.

Internet dos negócios. Programa Ver e Rever, 1998.
VASSOS, T.

Marketing estratégico na

Internet. Indianápolis : Que Corporation, 1997. 